\title{
Simple Approaches for the Synthesis of AgNPs in Solution and Solid Phase Using Modified Methoxypolyethylene Glycol and Evaluation of Their Antimicrobial Activity
}

This article was published in the following Dove Press journal: International Journal of Nanomedicine

\author{
Ayman El-Faham (D) ${ }^{1,2}$ \\ Hessa H Al-Rasheed' \\ Essam N Sholkamy ID $^{3}$ \\ Sameh M Osman ${ }^{1,4}$ \\ Zeid A ALOthman (iD) ${ }^{1,4}$ \\ 'Department of Chemistry, College of \\ Science, King Saud University, Riyadh \\ I I45I, Saudi Arabia; ${ }^{2}$ Department of \\ Chemistry, Faculty of Science, Alexandria \\ University, Ibrahimia, Alexandria 2132I, \\ Egypt; ${ }^{3}$ Department of Botany and \\ Microbiology, College of Science, King \\ Saud University, Riyadh II45I, Saudi \\ Arabia; ${ }^{4}$ Advanced Materials Research \\ Chair, Department of Chemistry, College \\ of Science, King Saud University, Riyadh \\ I|45I, Saudi Arabia
}

Purpose: Simple methodology for preparation of metal nanoparticles such as AgNPs uses an methanolic aqueous medium at room temperature or a solvent-free procedure under microwave irradiation. The prepared AgNPs showed a significant antimicrobial effect against Gram-positive bacteria, Gram-negative bacteria, and fungi.

Methods: The modified methoxypolyethylene glycol bishydrazino-s-triazine (mPEGTH2) showed remarkable activity for reducing $\mathrm{Ag}^{+}$to $\mathrm{Ag}^{0}$ in an aqueous methanolic solution and using a solvent-free method (solid phase) under microwave irradiation. In the solid phase synthesis, the size and shape of the AgNPs can be controlled by varying the weight ratio of mPEGTH2 to $\mathrm{AgNO}_{3}$ used. In addition, the antimicrobial activity depends on the ratio of mPEGTH2 to $\mathrm{AgNO}_{3}$. The mPEGTH2-AgNPs (2:1) demonstrated higher antimicrobial activity compared to mPEGTH2AgNPs (1:1) against Gram-positive bacteria, Gram-negative bacteria, and C.albicans.

Results: This work presents simple methods for the synthesis of AgNPs using modified methoxypolyethylene glycol with bishydrazino-s-triazine (mPEGTH2); a solution method, using methanol-water medium at room temperature, and a solvent-free (solid phase) method, employing microwave irradiation or direct heating which could be used for the preparation of AgNPs on large scale. In the solid phase, ratios of mPEGTH2 to $\mathrm{AgNO}_{3}$ (1:1 or 2:1, respectively) are very important to control the size and shape of AgNPs. While in solution phase is not necessary where the molar ratio used is 10:1. Most of the experimental methods resulted in AgNPs ranging in size from 7 to $10 \mathrm{~nm}$ as observed from XRD and TEM characterization. The antimicrobial activity of the AgNPs was also dependent on the weight ratio of mPEGTH2 to $\mathrm{AgNO}_{3}$, with a large effect as observed when using the solvent-free method. The mPEGTH2AgNPs (2:1) demonstrated higher antimicrobial activities compared to mPEGTH2-AgNPs (1:1) against $S$. aureus, S. epidermidis, E. faecalis, E. coli, P. aeruginosa, S. typhimurium, and C. albicans. In all cases, the MICs and MBCs of mPEGTH2-AgNPs $(1: 1)$ were lower than those of mPEGTH2-AgNPs $(2: 1)$.

Conclusion: In summary, mPEGTH2-AgNPs $(2: 1)$ is a promising candidate to kill pathogenic microbes. In particular, the method used for the preparation of AgNPs by using polyethylene glycol polymer modified with bishydrazino-s-triazine has the most potential and would be the most cost-effective method. This method of the synthesis of nanoparticles may be suitable for the preparation of other metal nanoparticles, which would allow for numerous applications in medicinal and industrial.

Keywords: methoxypolyethylene glycol bishydrazino-s-triazine, silver nanoparticles, solution phase, solid phase, antimicrobial activity
Tel +966114673195

Fax+966II4675992

Email aelfaham@ksu.edu.sa 


\section{Introduction}

Nanoparticles have important roles in materials science, chemistry, physics, medicine, and numerous other fields. ${ }^{1-4}$ Therefore, there is a strong need to create a new methodology for the synthesis of metal nanoparticles in large scale. Silver nanoparticles are utilized with increasing frequency in various fields, including medicine and agriculture, due to their unique physical and chemical properties. ${ }^{5}$ Most notably, AgNPs have been used for pharmaceutical applications, such as antibacterial ${ }^{6}$ agents and anticancer agents. ${ }^{7,8}$ Recently, the use of AgNPs has expended to other applications, such as textiles, wound dressings, and biomedical devices. $^{9-11}$

Various methods have been used for the preparation of AgNPs. Generally, the synthesis of nanoparticles has been carried out using three different approaches: Physical methods; ${ }^{12,13}$ chemical methods using water or organic solvents; ${ }^{1,14,15}$ and biological methods. ${ }^{16-19}$

Chemical methods usually employ three main components, which are metal precursors, reducing agents, and stabilizing/capping agents. The major advantage of chemical methods is that they have high yields compared to that of physical methods. On the other hand, chemical methods are tremendously expensive; additionally, the materials used for AgNPs synthesis, such as citrate, borohydride, thioglycerol, and 2-mercaptoethanol are toxic and hazardous materials. Furthermore, during the synthesatic process, numerous toxic and hazardous byproducts are generated. $^{20}$

Unlike chemical methods used for AgNPs synthesis, biological methods ${ }^{21}$ are simple, rapid, non-toxic, dependable, and green; additionally, the AgNPs produced are of well-defined size and morphology under optimized conditions. However, particle characterization is necessary because the physicochemical properties of the particles could have a significant impact on their biological properties. $^{22,23}$

Several methods have been presented for the synthesis of AgNPs using green, cost effective, and biocompatible methods without the use of toxic chemicals. In this green chemistry approach, researchers have used several different types of bacteria. $^{21,24-26}$ Additionally, several biomolecules, such as biopolymers, ${ }^{27}$ starch, ${ }^{28}$ and amino acids ${ }^{29}$ have been used. The use of biological molecules for the synthesis of AgNPs is eco-friendly and environmentally safe, and appeared to be useful for controlling of particle size and shape, which is an important factor in biomedical applications. ${ }^{30,31}$
Poly(ethylene glycol) (PEG) is a biocompatible polymer used extensively in many fields, including drug delivery, gene delivery, lithium polymer electricity storage systems, etc. ${ }^{32}$ Two approaches have been previously used to activate the hydroxyl terminal of PEG through the changing the hydroxyl group to a more reactive group. $^{33}$

In addition, methoxypolyethylene glycol (mPEG) is a mono-protected form of PEG that is a biocompatible polymer and has unique properties that make it particularly useful for many pharmaceutical applications. ${ }^{34}$ The unique solubility behavior of mPEG in water and several organic solvents allowed mPEG and its derivatives to be easily to purify from low molecular weight organic impurities by using simple methods, such as precipitation and centrifugation. However, the hydroxyl group of $\mathrm{mPEG}$ is not reactive enough to allow direct reaction with other molecules. Thus, the terminal hydroxyl group of the mPEG must be derivatized to a more reactive group to allow for reaction with other groups present in the biomolecule. Cyanuric chloride (2,4,6-trichloro-s-triazine) is typically used to activate the terminal hydroxyl group of mPEG due to its low cost, commercially availability, chemo-selective reactivity, and biocompatibility due to its having three reactive sites. ${ }^{35-38}$

In this regard, we report here the synthesis of an $\mathrm{mPEG}$ bishydrazino- $s$-triazine derivative and its use as a reducing agent to produce AgNPs using solution phase (methanolwater) or solvent-free method (solid phase) under microwave irradiation, the antimicrobial activity of the synthesized AgNPs was evaluated as well.

\section{Materials and Methods}

Methoxypolyethylene glycol (mPEG) with molecular weight 2000 or 5000 and 2,4,6-trichloro-s-triazine (cyanuric chloride) were purchased from Sigma-Aldrich. The $\mathrm{AgNO}_{3}$ salt was purchased from Merck. All of the chemicals used were analytical grade and were used without further purification. A Fourier transform infrared (FT-IR) spectrometer (Nicolet, NEXUS-670); a UV-vis spectrophotometer (Shimadzu UV-1208 model); and an X-ray diffractometer (XRD) (X'Pert PRO, PANalytical BV, Almelo, the Netherlands) using $\mathrm{CuK}_{\alpha}$ radiation were used for the characterization of AgNPs. ${ }^{39}$ Transmission electron microscopy (TEM), equipped with energy dispersive X-ray (EDX) analysis, was used to study the size, morphology, and composition of the AgNPs. Histograms of the size distribution of the AgNPs were calculated from 
the TEM images by measuring the diameters of at least 50 particles. ${ }^{39}$

\section{Synthesis of Methoxypolyethylene Glycol Dichloro-s-Triazine (mPEGTC2)}

Methoxypolyethylene glycol (mPEG, $20 \mathrm{~g}$ of 2000 M.wt. or $50 \mathrm{~g}$ of $5000 \mathrm{M}$.wt.) was dissolved in anhydrous benzene $(200 \mathrm{~mL})$, and then cooled to a temperature between $5^{\circ} \mathrm{C}$ and $10^{\circ} \mathrm{C}$. Cyanuric chloride (fivefold molar excess, $9.2 \mathrm{~g}$ in $200 \mathrm{~mL}$ benzene) was slowly added to the solution of $\mathrm{mPEG}$, followed by the addition of anhydrous sodium carbonate (5.25 g, fivefold molar excess). The reaction mixture was stirred at room temperature for $24 \mathrm{~h}$, and then the solid inorganic salt was filtered out of solution. Excess petroleum ether 40/60 was added to the filtrate and mPEGTC2 derivative was precipitated as a white solid. The precipitate was collected, then dissolved in benzene $(200 \mathrm{~mL})$ and precipitated again with petroleum ether $40 /$ 60. This process was repeated twice to remove any unreacted cyanuric chloride and afford the pure intermediate product in $82-84 \%$ yield.

\section{Synthesis of Methoxypolyethylene Glycol Bishydrazino-s-Triazine (mPEGTH2)}

The synthesized mPEGTC2 (10 g) was suspended in $200 \mathrm{~mL}$ of ethanol, followed by the slow addition of $20 \mathrm{~mL}$ of hydrazine hydrate $(80 \%)$ under stirring at room temperature. The reaction mixture was refluxed for 6 to $8 \mathrm{~h}$, and then cooled to room temperature; the excess solvent and hydrazine hydrate were removed under vacuum. The crude product was treated with excess ether to afford a white solid, which was collected by filtration, washed with ether, and then dried under vacuum to produce the final product, $\mathrm{mPEGTH} 2$, in nearly quantitative yield.

\section{Synthesis of Silver Nanoparticles Liquid Phase Synthesis of AgNPs at Room Temperature}

A solution of $10^{-3} \mathrm{M} \mathrm{AgNO}_{3}$ in $20 \mathrm{~mL}$ of deionized water was added to a suspended solution of $10^{-2} \mathrm{M}$ mPEGTH2 in $20 \mathrm{~mL}$ methanol with stirring at room temperature. Stirring of the reaction mixture was continued for $24 \mathrm{~h}$. The color of the solution changed from colorless to yellowish-red then to black (Figure S1). The AgNPs were collected using an ultracentrifuge (8000 rpm), washed with aqueous methanol, and then dried under vacuum.
Solid Phase (Solvent-Free) Synthesis of AgNPs Using Conventional Heating

$\mathrm{AgNO}_{3}$ salt was mixed with mPEGTH2 in two weight ratios (1:1 and 1:2, respectively) and then heated directly at $80^{\circ} \mathrm{C}$ for $30-\mathrm{sec}$ (at 5 -sec intervals) with continuous mixing; during heating, the color changed from white to grey and then to dark grey. The mixed solid product was washed with aqueous methanol, then collected using ultracentrifuge, and then dried under vacuum for $24 \mathrm{~h}$.

\section{Solid Phase (Solvent-Free) Synthesis of AgNPs Using Microwave Irradiation}

The $\mathrm{AgNO}_{3}$ was mixed well with mPEGTH2 in two different weight ratios (1:1 and 1:2, respectively) at room temperature. The solid mixture was heated using microwave irradiation at $60^{\circ} \mathrm{C}, 600 \mathrm{~W}$ for 5 -sec to 10 -sec. The AgNPs were suspended in a 1:1 methanol-water mixture, collected using an ultracentrifuge, washed with aqueous methanol, and then dried under vacuum.

\section{Biology}

\section{Test-Microorganism}

The antibacterial activities of mPEGTH2Ag (2:1) and mPEGTH2Ag (1:1) were assessed against two bacterial groups and one fungus. Gram-positive bacteria (Staphylococcus aureus ATCC 29213, Staphylococcus epidermidis ATCC 12228, and Enterococcus faecalis ATCC 29212) and Gram-negative bacteria (Escherichia coli ATCC 25922, Pseudomonas aeruginosa ATCC 27853, and Salmonella typhimurium ATCC 14028) were maintained in a Brain Heart Infusion (BHI) medium at $20^{\circ} \mathrm{C}$; $300 \mathrm{~mL}$ of each stock culture was added to $3 \mathrm{~mL}$ of BHI broth. Overnight cultures were kept for $24 \mathrm{~h}$ at $37 \pm 1^{\circ} \mathrm{C}$. After $24 \mathrm{~h}$ of incubation, the purity was checked, and the bacterial suspension (inoculum) was diluted with a sterile physiological solution (for the diffusion and indirect bioautographic tests) to $10^{8} \mathrm{CFU} / \mathrm{mL}$ (turbidity = McFarland barium sulfate standard 0.5). In the case of the fungus Candida albicans ATCC 60193, the medium used for antagonistic activity against tested fungi was Potato Dextrose Agar (PDA).

\section{Antimicrobial Activity Evaluation (Well Diffusion Method)}

The samples of mPEGTH2Ag (2:1 and 1:1) were prepared at a concentration of $3 \mathrm{mg} / \mathrm{mL}$, dissolved in dimethylsulfoxide (DMSO). Preparation of sterilized Mueller-Hinton agar plates seeded with pathogenic bacteria was performed; $60 \mu \mathrm{L}$ of each ratio of mPEGTH2Ag was 
prepared and placed in wells on the agar plates. The bacterial plates were incubated at $37^{\circ} \mathrm{C}$ for $24 \mathrm{~h}$, while in case of fungi; the used medium in antagonistic activity against tested fungi. ${ }^{40}$ Antimicrobial activities were determined by the inhibition zone after incubation. Discs of gentamicin $(30 \mu \mathrm{g})$ was used as a positive control in all of the experiments.

\section{Minimum Inhibitory Concentration (MIC) Determination}

The antibacterial activity of mPEGTH2Ag (2:1) and mPEGTH2Ag (1:1) was studied by employing a microdilution method, using Mueller-Hinton broth according to the clinical and laboratory standards institute (CLSI) guideline. ${ }^{41}$ The inoculum was prepared as described previously. Stock concentrations of mPEGTH2Ag (2:1) and mPEGTH2Ag (1:1) were both $3 \mathrm{mg} / \mathrm{mL}$. Further 1:2 serial dilutions were performed by addition of the culture broth to reach concentrations ranging from 1.5 to $0.235 \mathrm{mg} / \mathrm{mL}$. Then, $90 \mu \mathrm{L}$ samples of the different dilutions were distributed in separate wells of a 96-well plate, as well as a sterility control and a growth control (containing culture broth plus DMSO, without antimicrobial substance). Each test and growth control well was inoculated with $10 \mu \mathrm{L}$ of a bacterial suspension $\left(10^{8} \mathrm{CFU} / \mathrm{mL}\right)$. All experiments were performed in triplicate and the micro-dilution trays were incubated at $37{ }^{\circ} \mathrm{C}$ for $24 \mathrm{~h}$. After incubation, the culture broth of each dilution was inoculated on nutrient agar to detect MIC and MBC.

\section{Results and Discussion}

\section{Synthesis of mPEGTH2}

The chemical reduction method is the most commonly used method for the production of silver nanoparticles (AgNPs) despite the fact that it requires toxic and hazardous inputs and produces environmentally harmful byproducts. $^{22}$ In order to avoid using and producing toxic substances, many green methods have been reported. ${ }^{42,43}$
In this respect and in our ongoing research for the synthesis of metal nanoparticles (MNPs), ${ }^{39}$ we report here that the modification of mPEG to mPEG-bishydrazino- $s$ triazine derivative (mPEGTH2) and its application to the synthesis of AgNPs by employing methanolic aqueous medium or solvent-free conditions under microwave irradiation or conventional heating to provide a suitable alternative to traditional, chemical-based methods for the synthesis of AgNPs.

In the first step of this method, $\mathrm{mPEG}$ was activated using cyanuric chloride 1 to afford the dichloro-s-triazine derivative $\mathrm{MPEGTC2} 2$, and then reacted with hydrazine hydrate to afford the bishydrazino-s-triazine derivative mPEGTH2 $\mathbf{3}$ in approximately quantitative yield (Scheme 1).

The FTIR of mPEGTH2 showed two sharp peaks at 3540 and $3420 \mathrm{~cm}^{-1}$ related to the $\mathrm{NH}$ (NH stretching vibration) of the hydrazino groups, 2860 showed weak $\mathrm{C}-\mathrm{H}$ stretch, and $1560 \mathrm{~cm}^{-1}$ (NH bending vibration), and $1097 \mathrm{~cm}^{-1}$ (C-O stretching vibration) (Figure S2).

\section{Synthesis of AgNPs}

The first approach was using an aqueous solution method in which a solution of $\mathrm{AgNO}_{3}$ was added to a methanolic solution of mPEGTH2 at room temperature and the mixture was gently stirred overnight at room temperature to reduce the $\mathrm{Ag}^{+}$to $\mathrm{Ag}^{\mathrm{O}}$. The color of the solution changed from colorless, to yellow, and then to red (Figure S1). The AgNPs were collected using an ultracentrifuge for $20 \mathrm{~min}$ (8000 rpm), dried, and then characterized using several techniques. The proposed mechanism for reduction of $\mathrm{Ag}^{+}$ to $\mathrm{Ag}^{\mathrm{O}}$ is illustrated in Scheme 2. From this proposed mechanism, it is implied that the presence of van der Waals forces between the positive charge of $\mathrm{Ag}^{+}$and the oxygen of the mPEGTH2 increase the capping efficiency of mPEGTH2 for the surface of the AgNPs. ${ }^{44}$

In the second approach, both the microwave irradiation and the conventional heating assisted the reduction of $\mathrm{Ag}^{+}$ to $\mathrm{Ag}^{\mathrm{o}}$ via dimerization. This is likely due to the aggregation of $\mathrm{Ag}$ clusters into nanoparticles (Scheme 2). ${ }^{45} \mathrm{In}$

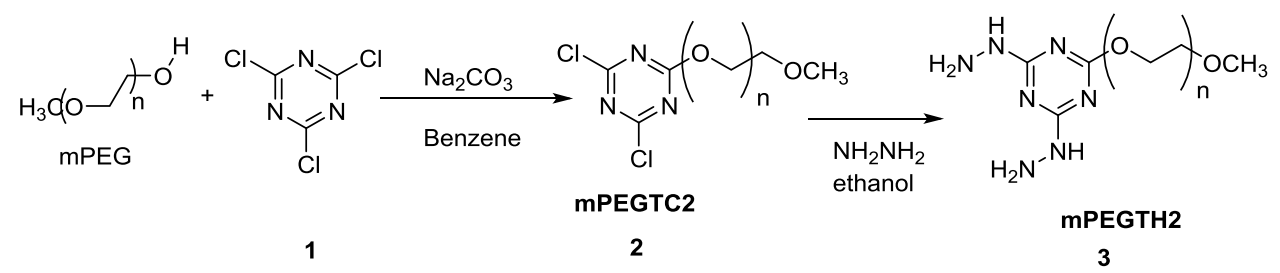

Scheme I Synthesis of mPEGTH2. 


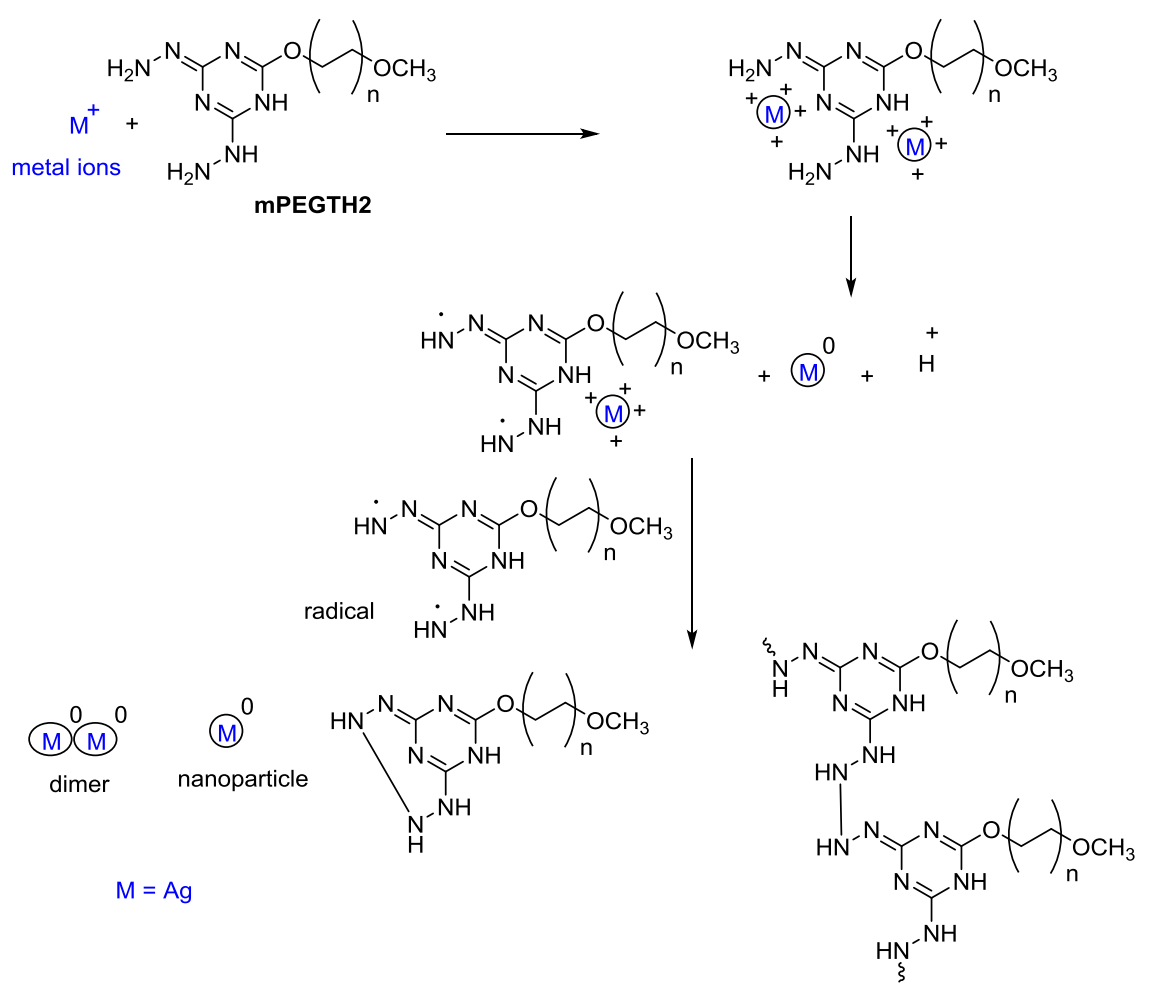

Scheme 2 Synthesis of mPEGTH2AgNPs.

addition, increasing the weight ratio of mPEGTH2 to $\mathrm{AgNO}_{3}$ (from 1:1 to $2: 1$, respectively, for the solventfree method), is recommended to enhance the reduction step and ensure the capping of AgNPs. In addition, increasing the ratio of $\mathrm{mPEGTH} 2$ would also help to control the particle size of AgNPs and increase their stability for several months in typical environmental conditions.

\section{Characterization of AgNPs \\ FTIR and UV-Spectroscopy Characterization}

The FTIR spectrum for the mPEGTH2-AgNPs (Figure S3) was analyzed to identify the active group of the mPEGTH2, which are responsible for the reduction of the $\mathrm{Ag}^{+}$to $\mathrm{Ag}^{\mathrm{o}}$. The FTIR results of mPEGTH2-AgNPs showed broad absorption peak at $3450 \mathrm{~cm}^{-1}$ related to the NH (stretching vibration) of the hydrazino groups, 2885 weak $-\mathrm{C}-\mathrm{H}$ stretch, and peak at $1467 \mathrm{~cm}^{-1}$ for the $\mathrm{NH}$ (bending vibration), $1360 \mathrm{~cm}^{-1}$ represented the $\mathrm{CH}_{2}$ bending and the $1109 \mathrm{~cm}^{-1}$ represented the C-O stretching vibration.

The broadness of the peaks at $3444 \mathrm{~cm}^{-1}$ for the $\mathrm{NH}$ groups, confirmed that the hydrazine group responsible for the reduction of $\mathrm{Ag}^{+}$to $\mathrm{Ag}^{0}$. The obtained data agreed with the proposed mechanism shown in Scheme 2 for the formation of AgNPs.

The UV-visible spectroscopy (Figure 1) also confirmed the formation of AgNPs in the presence of mPEGTH2. A strong and slightly broadband for mPEGTH2Ag was observed at $424 \mathrm{~nm}$. This band is correlated to the surface plasmon absorption band, which explains the formation of the uniform, dispersed spherical AgNPs capped with

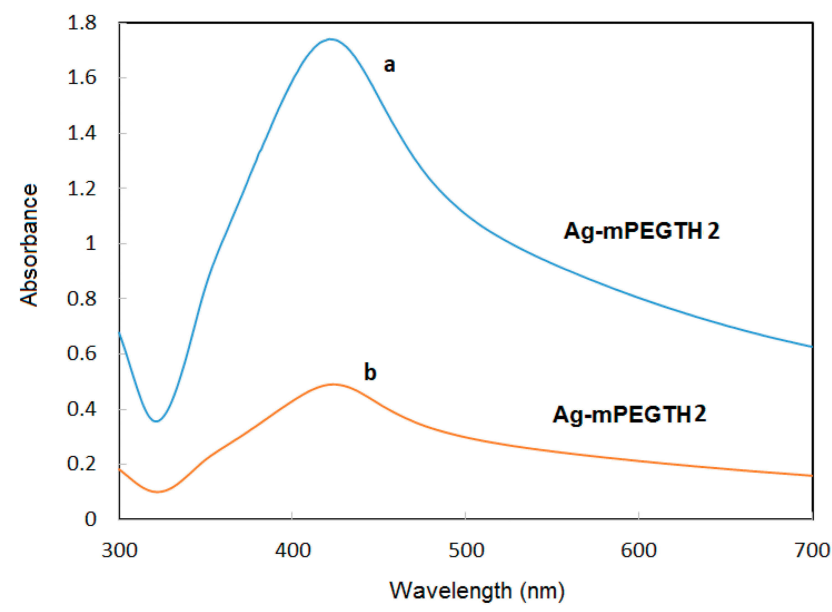

Figure I UV-visible spectra of AgNPs coated with different weight ratio of mPEGTH2. (A) AgNPs from $\mathrm{AgNO}_{3}: \mathrm{mPEGTH}_{2} \mathrm{I:2} \mathrm{w} / \mathrm{w}$; (B) AgNPs from $\mathrm{AgNO}_{3}: \mathrm{mPEGTH} 2$ I:I w/w. 
mPEGTH2 ${ }^{19,46}$ The broadness of the band decreased in intensity, with appearance of a shoulder at $375 \mathrm{~nm}$, for mPEGTH2-AgNPs $\left(\mathrm{AgNO}_{3}: \mathrm{mPEGTH} 2,1: 1\right)$ as shown in Figure 1A. This observation indicates an accumulation of AgNPs with the change in chemical structure of mPEGTH $2 .{ }^{44}$ The obtained data agreed with the proposed mechanism shown in Scheme 2 for the formation of AgNPs, confirming a dependence on the weight ratio of mPEGTH2 to $\mathrm{AgNO}_{3}$. This ratio is necessary in solid phase synthesis to control the size and shape of the AgNPs. While in case of the solution phase method, it is not necessary because the molar ratio used is $10: 1$ mPEGTH2: $\mathrm{AgNO}_{3}$.

\section{EDX and XRD Analysis}

The elemental analysis of the AgNPs was performed using EDX analysis, as represented in Figure 2; the EDX analysis confirmed the presence of the silver signal related to the AgNPs. Signal peaks were observed in the range of $2.5-4.0 \mathrm{keV}$, which corresponds to the binding energies of crystalline silver. ${ }^{47}$ The strong signal peak near $0.2 \mathrm{keV}$ corresponds to the carbon in the mPEGTH2, connected to the AgNPs. These results were confirmed by previous reports that showed that AgNPs are crystalline in nature, as supported by the same EDX results. ${ }^{19,47}$

The crystal structure of the mPEGTH2-Ag nanoparticles was determined from the XRD patterns, as represented in Figure 3 (solution and solid-phase method). The data show a broad peak at $2 \theta=20^{\circ}$, confirming the amorphous structure of mPEGTH2. The mPEGTH2-AgNPs sample showed peaks at about $38.1^{\circ}, 44.09^{\circ}$, $64.36^{\circ}, 77.29^{\circ}$, and $81.31^{\circ}$ for both of the prepared materials,

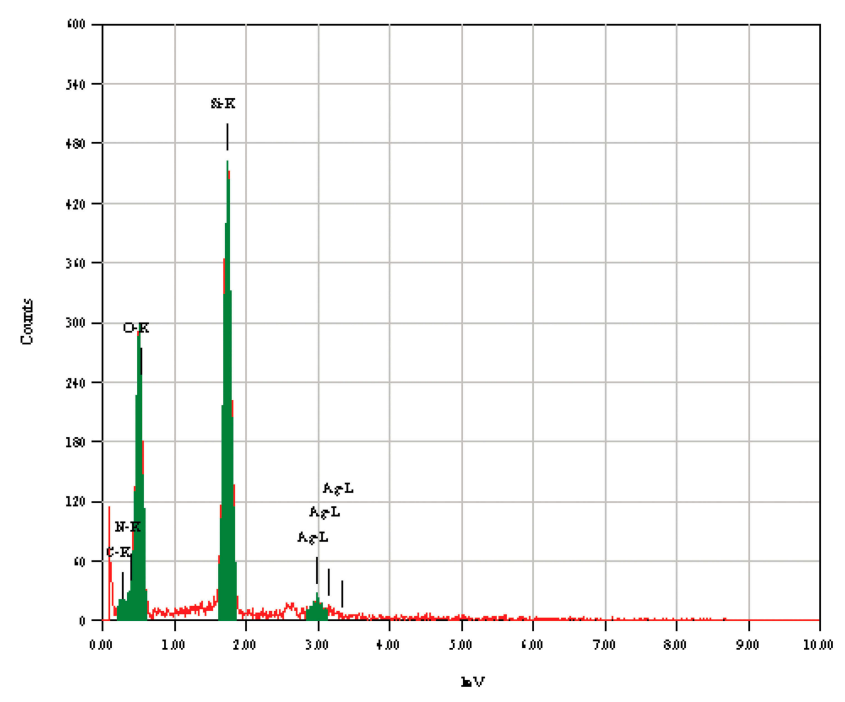

Figure 2 Energy dispersive X-ray spectra of the prepared AgNPs from solution.

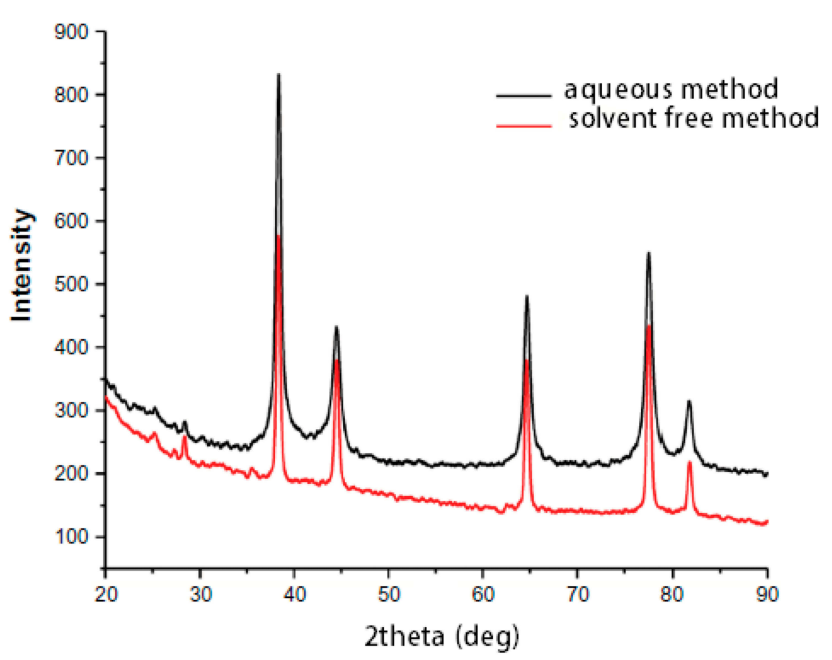

Figure 3 XRD results confirming the formation of AgNPs in an aqueous solution and solvent-free method.

which related to the $111,200,220,311,222,400,331$, and 420 planes, respectively. The intensive diffraction peak at $38.1^{\circ}$, which is related to the $\{111\}$ lattice plane of face-centered cubic silver, indicates that pure AgNPs were formed. ${ }^{21,48}$ The diffraction planes of the mPEGTH2-AgNPs indicated the presence of a typical face-centered cubic structure of silver, according to the available literature (Joint Committee on Powder Diffraction Standards, JCPDS file No 04-0783).

\section{TEM Analysis}

The uniform and well-dispersed spherical shape of the produced AgNPs and the resulting histogram were observed from the TEM images (Figure 4A-C). The uniform shape is caused by the good coordinating and capping capability of the $\mathrm{N}$-atom in $\mathrm{mPEGTH} 2$ to reduce the $\mathrm{Ag}^{+}$to $\mathrm{Ag}^{\mathrm{o}}$.

The Average particle sizes (D) were calculated using the following equation: ${ }^{39}$

$\mathrm{D}=0.9 \lambda / \beta \cos \theta$

where $\beta$ is the full-width at half-maximum of peaks and $\lambda$ is the $\mathrm{X}$-ray wavelength.

The data showed that the particle sizes of mPEGTH2AgNPs synthesized using the solvent-free and the solution phase methods (Figure 5), showed the formation of AgNPs with diameter of 7 to $10 \mathrm{~nm}$; this confirms that the weight ratio of mPEGTH2 related to the $\mathrm{AgNO}_{3}$ is important in coating all silver particles, especially in the solvent-free method.

\section{Antimicrobial Activity}

The antimicrobial activities for the prepared mPEGTH2-Ag nanoparticles were evaluated against selected microorganisms 

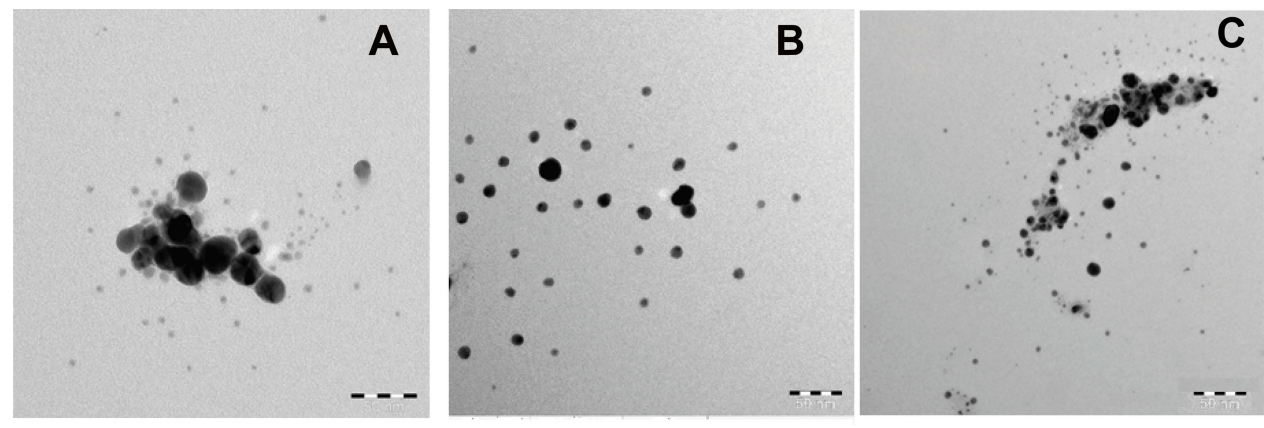

Figure 4 (A) TEM of AgNPs (solution phase) using mPEGTH2; (B) TEM of AgNPs (solid phase) using mPEGTH2 (I:I, AgNO 3 :mPEGTH2); (C) TEM of AgNPs (solid phase) using mPEGTH2 (I:2, $\left.\mathrm{AgNO}_{3}: \mathrm{mPEGTH} 2\right)$.

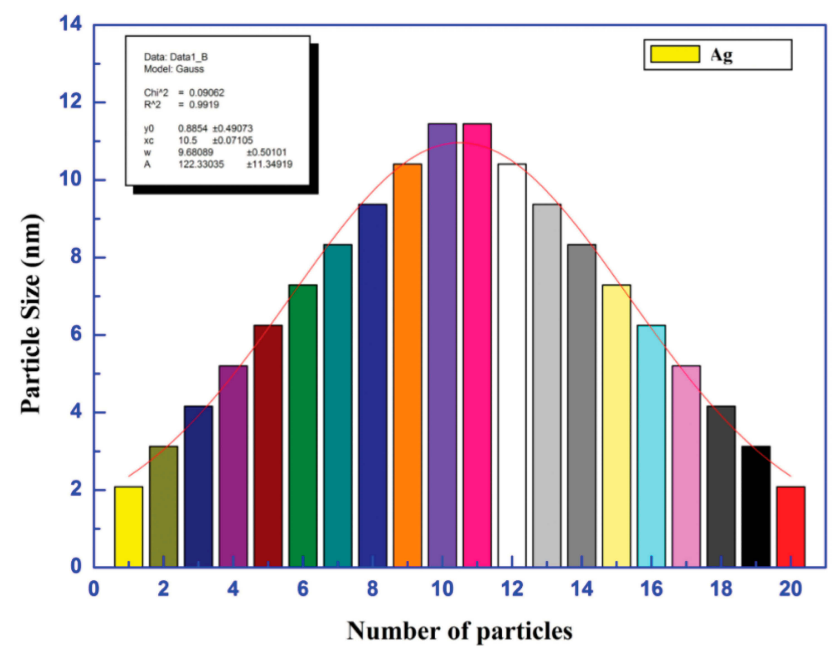

Figure 5 Particles size for silver nanoparticles.

(Table 1, Figure 6). The results indicated that mPEGPTH2AgNPs obtained from the weight ratio 2:1 (mPEGTH2: $\mathrm{AgNO}_{3}$ ) exhibited a wide range of antimicrobial activity against tested Gram-positive and Gram-negative bacteria, in addition to the inhibition of $C$. albicans. In addition, they are more effective than mPEGPTH2-AgNPs obtained from weight ratio 1:1 (mPEGTH2: $\mathrm{AgNO}_{3}$ ) (Table 1, Figure 6). The mPEGTH2-AgNPs (1:1) did not show any activity against $E$. faecalis, but did show bioactivity against other microorganisms, as shown in Table 1. While ligand (mPEGTH2) has no bioactivity compared with mPEGTH2-AgNPs (1:1) and mPEGTH2AgNPs (2:1). The results obtained in this study agree with the reported results by Abul et al, who reported that MK-AgNPs as an effective antibacterial agent against Gram-positive and Gram-negative bacteria. ${ }^{49}$

By the typical duplicate two-fold using dilution method, MICs and MBCs were determined for mPEGTH2-AgNPs (2:1) and mPEGTH2-AgNPs (1:1) against E. coli, S. epidermidis, and $C$. albicans. The results represented in Table 2 showed stronger bioactivity of mPEGTH2-AgNPs (2:1) compared to the bioactivity of mPEGTH2-AgNPs (1:1) against the tested pathogenic microbes. The results also revealed that mPEGTH2Ag (2:1) was a strong antifungal agent against $C$. albicans and a strong antibacterial agent against $S$. epidermidis. The obtained results agree well with the previously reported results for polyethylene glycol coated nanoparticles that were effective in killing all bacterial strains, including E. coli DH5a, Bacillus subtilis, Micrococcus luteus, and S. aureus. ${ }^{50,51}$ The results also agreed with the reported results by Popa et al; who reported that polyethylene glycol coated silver nanoparticles most stable and effective. ${ }^{52}$

\section{Conclusion}

This work represents simple and efficient methods for the synthesis of AgNPs using modified methoxypolyethylene glycol with bishydrazino-s-triazine mPEGTH2. The AgNPs were prepared using two methods; a solution method, using methanol-water medium at room temperature, and a solvent-free (solid phase) method, employing

Table I Determination of Microbial Growth Inhibition Diameters (Mm) by mPEGTH2Ag 2:I and mPEGTH2Ag (I:I)*

\begin{tabular}{|l|l|l|l|l|l|l|l|}
\hline Tested Compd & S. aureus & S. epidermidis & E. faecalis & E. coli & S. typhi & P. aeruginosa & C. albicans \\
\hline mPEGTH2Ag (I:I) & 10 & 15 & 0 & 11 & 0 & 10 & 17 \\
mPEGTH2Ag (2:I) & $1 \mathrm{I}$ & 18 & 18 & 20 & 14 & 17 & 13 \\
Gentamicin** & 25 & 23 & 17 & 22 & 20 & 19 & - \\
\hline
\end{tabular}

Notes: *DMSO was used as a negative control; **30 $\mu \mathrm{g}$ per disc. 

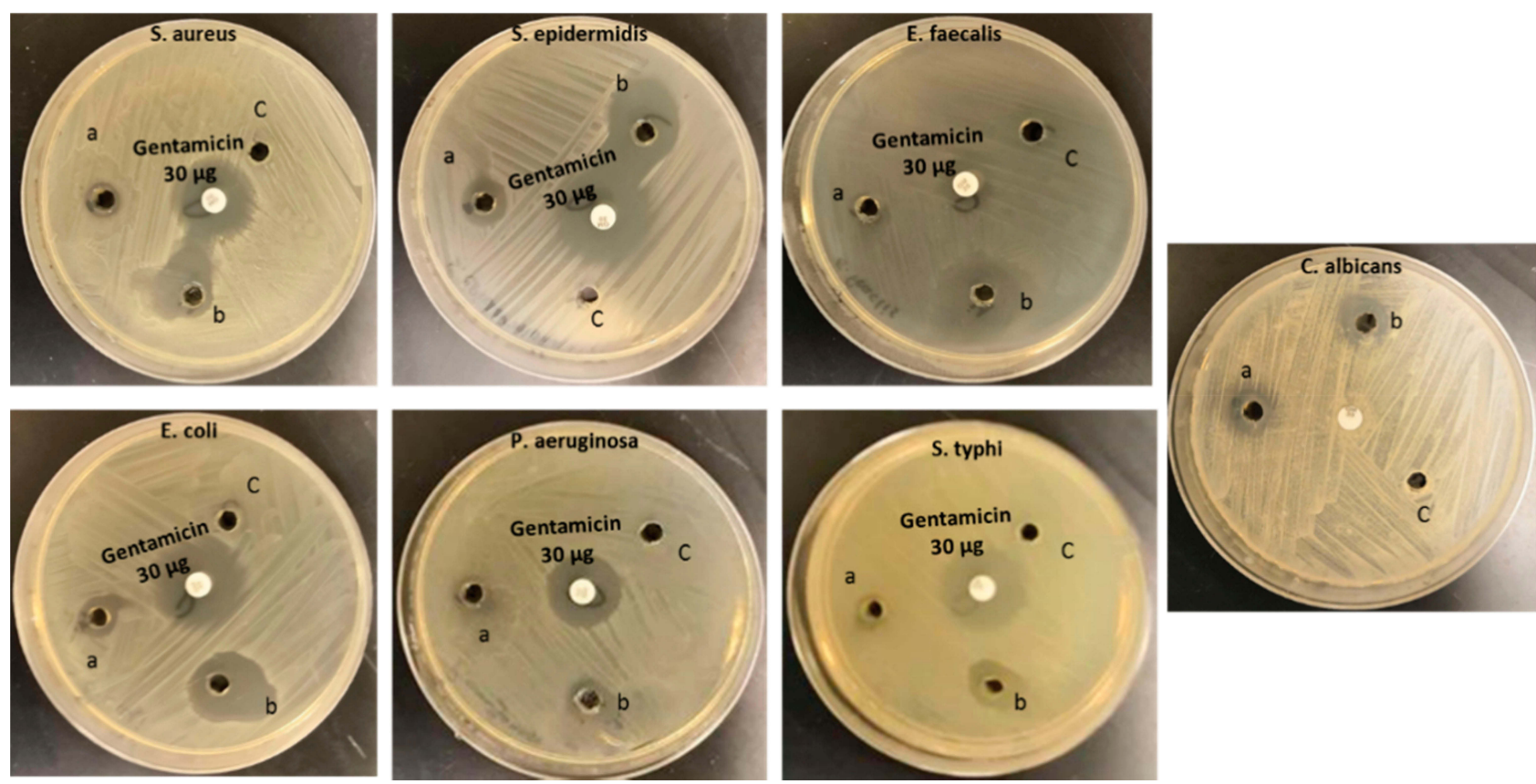

Figure 6 Growth inhibition images of target pathogenic microbes with (A) mPEGTH2-Ag NPs (I:I ratio); (B) mPEGTH2-Ag NPs (2:I ratio); (C) negative control DMSO alone.

microwave irradiation or direct heating. In aqueous solution, the ratio was 10:1 mPEGTH2: $\mathrm{AgNO}_{3}$, while in the solid phase, ratios of 1:1 or 2:1, respectively (wt./wt.) were used. Most of the experimental methods resulted in AgNPs ranging in size from 7 to $10 \mathrm{~nm}$. The formation of AgNPs was dependent on the weight ratio of mPEGTH2 to $\mathrm{AgNO}_{3}$, which allows for control of the size and shape of the AgNPs, especially when using the solvent-free method. The antimicrobial activity of the AgNPs was also dependent on the ratio of mPEGTH2 to $\mathrm{AgNO}_{3}$, with a large effect observed when using the solvent-free method. The mPEGTH2-AgNPs (2:1) demonstrated higher antimicrobial activity compared to mPEG-TH2Ag 1:1 against $S$. aureus, S. epidermidis, E. faecalis, E. coli, P. aeruginosa, S. typhimurium, and C. albicans. In all cases, the MICs and MBCs of mPEGTH2-AgNPs (1:1) were lower than those of mPEGTH2-AgNPs (2:1).

Table 2 Minimum Inhibitory (MIC) and Minimum Bactericidal Concentration (MBC) of mPEGTH2Ag (I:I) and mPEGTH2Ag (2:I) Against S. epidermidis, E. coli and C. albicans Growth

\begin{tabular}{|l|l|l|l|l|}
\hline \multirow{2}{*}{$\begin{array}{l}\text { Microbes } \\
\text { Mompd. }\end{array}$} & \multicolumn{2}{|l|}{ mPEGTH2-Ag (I:I) } & \multicolumn{2}{l|}{ mPEGTH2-Ag (2: I) } \\
\cline { 2 - 5 } & $\begin{array}{l}\text { MIC } \\
(\mathbf{m g} / \mathbf{m L})\end{array}$ & $\begin{array}{l}\text { MBC } \\
(\mathbf{m g} / \mathbf{m L})\end{array}$ & $\begin{array}{l}\text { MIC } \\
(\mathbf{m g} / \mathbf{m L})\end{array}$ & $\begin{array}{l}\text { MBC } \\
(\mathbf{m g} / \mathbf{m L})\end{array}$ \\
\hline E. coli & 0.375 & 0.563 & 0.282 & 0.375 \\
S. epidermidis & 0.375 & 0.563 & 0.094 & 0.188 \\
C. albicans & 0.282 & 0.375 & 0.036 & 0.047 \\
\hline
\end{tabular}

In summary, mPEGTH2-AgNPs (2:1) is a promising candidate to kill pathogenic microbes; in particular, the AgNPs synthesized using methoxypolyethylene glycol polymer modified by coating with bishydrazino- $s$-triazine have the most potential and would be the most cost-effective to produce. This method reported here for the synthesis of silver nanoparticles may be suitable for preparation AgNPs on large scale and could be applicable for other metal nanoparticles, which would allow them for numerous applications in medicine and industry.

\section{Acknowledgments}

The authors extend their appreciation to the Researchers Supporting Project at King Saud University, Riyadh, Saudi Arabia, for funding this work through Project No. (RSP2019/50).

\section{Author Contributions}

All authors contributed to data analysis, drafting or revising the article, gave final approval of the version to be published, and agree to be accountable for all aspects of the work.

\section{Disclosure}

Professor Ayman El-Faham reports grants from Researchers Supporting Project at King Saud University, Riyadh, Saudi Arabia, Project No. (RSP-2019/50), outside 
the submitted work. In addition, Professor Ayman ElFaham has a patent issued: US Patent 9873153 B1. The authors report no other conflicts of interest in this work.

\section{References}

1. Zhang XF, Liu ZG, Shen W, Gurunathan S. Silver nanoparticles: synthesis, characterization, properties, applications, and therapeutic approaches. Int J Mol Sci. 2016;17(9):1534. doi:10.3390/ijms17091534

2. Fathima JB, Pugazhendhi A, Venis R. Synthesis and characterization of $\mathrm{ZrO} 2$ nanoparticles-antimicrobial activity and their prospective role in dental care. Microb Pathog. 2017;110:245-251. doi:10.1016/ j.micpath.2017.06.039

3. Pugazhendhia A, Kumar SS, Manikandan M, Saravanan M. Photocatalytic properties and antimicrobial efficacy of $\mathrm{Fe}$ doped $\mathrm{CuO}$ nanoparticles against the pathogenic bacteria and fungi. Microb Pathog. 2018;122:84-89. doi:10.1016/j.micpath.2018.06.016

4. Sim W, Barnard RT, Blaskovich MAT, Ziora ZM. Antimicrobial silver in medicinal and consumer applications: a patent review of the past decade (2007-2017). Antibiotics. 2018;7:93. doi:10.3390/antibiotics7040093

5. Shanmuganathan R, Karuppusamy I, Saravanan M, et al. Synthesis of silver nanoparticles and their biomedical applications - a comprehensive review. Curr Pharm Des. 2019;25:2650-2660. doi:10.2174/ 1381612825666190708185506

6. Saravanan M, Arokiyaraj S, Lakshmi T, Pugazhendhi A. Synthesis of silver nanoparticles from Phenerochaete chrysosporium (MTCC-787) and their antibacterial activity against human pathogenic bacteria Microb Pathog. 2018;117:68-72. doi:10.1016/j.micpath.2018.02.008

7. Pugazhendhi A, Edison TNJI, Karuppusamy I, Kathirvel B. Inorganic nanoparticles: a potential cancer therapy for human welfare. Int $J$ Pharm. 2018;539:104-111. doi:10.1016/j.ijpharm.2018.01.034

8. Gurunathan S, Park JH, Han JW, Kim JH. Comparative assessment of the apoptotic potential of silver nanoparticles synthesized by Bacillus tequilensis and Calocybe indica in MDA-MB-231 human breast cancer cells: targeting p53 for anticancer therapy. Int J Nanomed. 2015;10:4203-4222. doi:10.2147/IJN.S83953

9. Li CY, Zhang YJ, Wang M, et al. In vivo real-time visualization of tissue blood flow and angiogenesis using $\mathrm{Ag}_{2} \mathrm{~S}$ quantum dots in the NIR-II window. Biomaterials. 2014;35:393-400. doi:10.1016/j. biomaterials.2013.10.010

10. Shanmuganathan R, MubarakAli D, Prabakar D, et al. An enhancement of antimicrobial efficacy of biogenic and ceftriaxone-conjugated silver nanoparticles: green approach. Environ Sci Pollut Res. 2018;25(11):10362-10370. doi:10.1007/s11356-017-9367-9

11. Möhler JS, Simc W, Blaskovich MAT, Cooper MA, Ziora ZM. Silver bullets: a new lustre on an old antimicrobial agent. Biotech Adv. 2018;36:1391-1411. doi:10.1016/j.biotechadv.2018.05.004

12. Kruis FE, Fissan H, Rellinghaus B. Sintering and evaporation characteristics of gas-phase synthesis of size-selected $\mathrm{PbS}$ nanoparticles. Mater Sci Eng B. 2000;69:329-334. doi:10.1016/S0921-5107(99)00298-6

13. Lin PC, Lin S, Wang PC, Sridhar R. Techniques for physicochemical characterization of nanomaterials. Biotechnol Adv. 2014;32:711-726. doi:10.1016/j.biotechadv.2013.11.006

14. Gurunathan S, Han JW, Kwon DN, Kim JH. Enhanced antibacterial and anti-biofilm activities of silver nanoparticles against Gram-negative and Gram-positive bacteria. Nanoscale Res Lett. 2014;9:373. doi:10.1186/1556-276X-9-373

15. Mallick K, Witcomb MJ, Scurrell MS. Polymer stabilized silver nanoparticles: a photochemical synthesis route. J Mater Sci. 2004;39:4459-4463. doi:10.1023/B:JMSC.0000034138.80116.50

16. Pugazhendhi A, Prabakar D, Jacob JM, Karuppusamy I, Saratale RG. Synthesis and characterization of silver nanoparticles using Gelidium amansii and its antimicrobial property against various pathogenic bacteria. Microb Pathog. 2018;114:41-45. doi:10.1016/j.micpath. 2017.11.013
17. Qi L, Liu Z, Wang N, Hu Y. Facile and efficient in situ synthesis of silver nanoparticles on diverse filtration membrane surfaces for antimicrobial performance. Appl Surf Sci. 2018;456:95-103. doi:10.1016/j.apsusc.2018.06.066

18. Saravanan M, Barik SK, MubarakAli D, Prakash P, Pugazhendhi A. Synthesis of silver nanoparticles from Bacillus brevis (NCIM 2533) and their antibacterial activity against pathogenic bacteria. Microb Pathog. 2018;116:221-226. doi:10.1016/j.micpath.2018.01.038

19. Samuel MS, Jose S, Selvarajan E, Mathimani T, Pugazhendhi A. Biosynthesized silver nanoparticles using Bacillus amyloliquefaciens; application for cytotoxicity effect on A549 cell line and photocatalytic degradation of p-nitrophenol. $J$ Photochem Photobiol $B$. 2020;202:1116423. doi:10.1016/j.jphotobiol.2019.111642

20. Murdock RC, Braydich-Stolle L, Schrand AM, Schlager JJ, Hussain SM. Characterization of nanomaterial dispersion in solution prior to in vitro exposure using dynamic light scattering technique. Toxicol Sci. 2008;101(2):239-253. doi:10.1093/toxsci/kfm240

21. Jacob JM, John MS, Jacob A, et al. Bactericidal coating of paper towels via sustainable biosynthesis of silver nanoparticles using Ocimum sanctum leaf extract. Mater Res Express. 2019;6 (4):045401. doi:10.1088/2053-1591/aafaed

22. Jo DH, Kim JH, Lee TG, Kim JH. Size, surface charge, and shape determine therapeutic effects of nanoparticles on brain and retinal diseases. Nanomedicine. 2015;11:1603-1611.

23. Albanese A, Tang PS, Chan WC. The effect of nanoparticle size, shape, and surface chemistry on biological systems. Ann Rev Biomed Eng. 2012;14(1):1-16. doi:10.1146/annurev-bioeng-071811-150124

24. Gour A, Kumar NJ. Advances in green synthesis of nanoparticles. Artif Cells Nanomed Biotech. 2019;47(1):844-851. doi:10.1080/ 21691401.2019.1577878

25. Gurunathan S, Han JW, Dayem AA, et al. Green synthesis of anisotropic silver nanoparticles and its potential cytotoxicity in human breast cancer cells (MCF-7). J Ind Eng Chem. 2013;19:1600-1605.

26. Gurunathan S, Jeong JK, Han JW, Zhang XF, Park JH, Kim JH. Multidimensional effects of biologically synthesized silver nanoparticles in Helicobacter pylori, Helicobacter felis, and human lung (L132) and lung carcinoma A549 cells. Nanoscale Res Lett. 2015;10:1-17. doi:10.1186/s11671-015-0747-0

27. Gurunathan S. Biologically synthesized silver nanoparticles enhances antibiotic activity against Gram-negative bacteria. J Ind Eng Chem. 2015;29:217-226. doi:10.1016/j.jiec.2015.04.005

28. Leung TC, Wong CK, Xie Y. Green synthesis of silver nanoparticles using biopolymers, carboxymethylated-curdlan and fucoidan. Mater Chem Phys. 2010;121(3):402-405. doi:10.1016/j.matchemphys.2010.02.026

29. Kumar B, Smita K, Cumbal L, Debut A, Pathak RN. Sonochemical synthesis of silver nanoparticles using starch: a comparison. Bioinorg Chem Appl. 2014;2014:784268. doi:10.1155/2014/784268

30. Shankar S, Rhim JW. Amino acid mediated synthesis of silver nanoparticles and preparation of antimicrobial agar/silver nanoparticles composite films. Carbohyd Polym. 2015;130:353-363. doi:10.1016/ j.carbpol.2015.05.018

31. Suganya M, Gnanamangai BM, Govindasamy C, et al. Mitochondrial dysfunction mediated apoptosis of HT-29 cells through CS-PACAgNPs and investigation of genotoxic effects in zebra (Danio rerio) fish model for drug delivery. Saudi J Biological Sci. 2019;26:767776. doi:10.1016/j.sjbs.2019.03.007

32. Zalipsky S, Gilon C, Zilkha A. Attachment of drugs to polyethylene glycols. Eur Polym J. 1983;19(12):1177-1183. doi:10.1016/00143057(83)90016-2

33. Namazi H, Adeli M. Solution proprieties of dendritic triazine/poly (ethylene glycol)/dendritic Triazine block copolymers. J Polym Sci. 2005;43(1):28-41. doi:10.1002/(ISSN)1099-0518

34. Armstrong JK, Hempel G, Koling S, et al. Antibody against poly (ethylene glycol) adversely affects PEG-Asparaginase therapy in acute Lymphoblastic Leukemia patients. Cancer. 2007;110(1):103111. doi:10.1002/(ISSN)1097-0142 
35. Sohrabi N, Rasouli N, Torkzadeh M. Enhanced stability and catalytic activity of immobilized a-amylase on modified $\mathrm{Fe}_{3} \mathrm{O}_{4}$ nanoparticles. Chem Eng J. 2014;240:426-433. doi:10.1016/j.cej.2013.11.059

36. González M, Vaillard SE. Evolution of reactive $\mathrm{mPEG}$ polymers for the conjugation of peptides and proteins. Curr Org Chem. 2013;17:975-998. doi:10.2174/1385272811317090010

37. Odajima T, Onishi M. A chemical modification of myeloperoxidase and lactoperoxidase with 2-(O-methoxypolyethylene glycol)-4,6dichloro-s-triazine (Activated PEG1). Cell Biochem Fun. 1998;16:123-128. doi:10.1002/(SICI)1099-0844(199806)16:2<123: AID-CBF777>3.0.CO;2-4

38. Falchi A, Taddei M. PEG-dichlorotriazine (PEG-DCT): a new soluble polymer-supported scavenger for alcohols, thiols, phosphines, and phosphine oxides. Org Lett. 2000;2(22):3429-3431. doi:10.1021/ ol0002222

39. Dahlous KA, Abd-Elkader OH, Fouda MMG, ALOthman ZA, ElFaham A. Eco-friendly method for silver nanoparticles immobilized decorated silica: synthesis \& characterization and preliminary antibacterial activity. J Taiwan Inst Chem Eng. 2019;95:423-431. doi:10.1016/j.jtice.2018.07.020

40. Wayne PA. CLSI Standard M07: Methods for Dilution Antimicrobial Susceptibility Tests for Bacteria That Grow Aerobically:. 11th ed. Clinical and Laboratory Standards Institute; 2018.

41. Textor T, Fouda MMG, Mahltig B. Deposition of durable thin silver layers onto polyamides employing a heterogeneous Tollens' reaction. Appl Surf Sci. 2010;256(8):2337-2342. doi:10.1016/j.apsusc.2009.10.063

42. El-Rafie MH, El-Naggar ME, Ramadan MA, Fouda MMG, Al-Deyab SS, Hebeish A. Environmental synthesis of silver nanoparticles using hydroxypropyl starch and their characterization. Carbohyd Polym. 2011;86(2):630-635. doi:10.1016/j.carbpol.2011.04.088

43. El-Aassar MR, Hafez EE, Fouda MMG, Al-Deyab SS. Synthesis, characterization, and antimicrobial activity of poly(acrylonitrile-comethyl methacrylate) with silver nanoparticles. Appl Biochem Biotechnol. 2013;171(3):643-654. doi:10.1007/s12010-013-0395-8
44. Wang B, Zhuang X, Deng W, Cheng B. Microwave-assisted synthesis of silver nanoparticles in alkalic carboxymethyl chitosan solution. Engineering. 2010;2:387-390. doi:10.4236/eng.2010.25050

45. Sharma S, Thakur M, Deb M. Synthesis of silver nanoparticles using $\mathrm{N}^{1}, \mathrm{~N}^{2}$-diphenylbenzamidine by microwave irradiation method. $J$ Exp Nanosci. 2007;2:251-256. doi:10.1080/17458080701753744

46. Stamplecoskie KG, Scaiano JC. Light emitting diode irradiation can control the morphology and optical properties of silver nanoparticles. J Am Chem Soc. 2010;132:1825-1827.

47. Gurunathan S, Kalishwaralal K, Vaidyanathan R, et al. Biosynthesis, purification and characterization of silver nanoparticles using Escherichia coli. Colloids Surf B. 2009;74:328-335. doi:10.1016/j. colsurfb.2009.07.048

48. Yagci Y, Sahin O, Ozturk T, Marchi S, Grassini S, Sangermano M. Synthesis of silver/epoxy nanocomposites by visible light sensitization using highly conjugated thiophene derivatives. React Funct Polym. 2011;71:857-862. doi:10.1016/j.reactfunctpolym.2011.05.012

49. Abul QF, Shafiq A, Khan HM, et al. Antibacterial effect of silver nanoparticles synthesized using murraya koenigii (L.) against multidrug-resistant pathogens. Bioinorg Chem Appl. 2019;2019:4649506. doi:10.1152/ajplegacy.1975.229.6.1641

50. Bhattacharya D, Samanta S, Mukherjee A, et al. Antibacterial activities of polyethylene glycol, tween 80 and sodium dodecyl sulphate coated silver nanoparticles in normal and multi-drug resistant bacteria. J Nanosci Nanotech. 2012;12:1-9. doi:10.1166/jnn.2012.6148

51. Wang AL, Yin HB, Ren M, Cheng Q, Zhou F, Zhang XF. Effect of different group containing organics on morphology controlled synthesis of nanoparticles at room temperature. Acta Metallurgica Sinica (Engl Letter). 2008;19(5):362-370. doi:10.1016/S1006-7191(06) 62074-7

52. Popa M, Pradell T, Crespo D, Calderón-Moreno JM. Stable silver colloidal dispersions using short chain polyethylene glycol. Colloids Surf A. 2007;303(3):184-190. doi:10.1016/j.colsurfa.2007.03.050
International Journal of Nanomedicine

\section{Publish your work in this journal}

The International Journal of Nanomedicine is an international, peerreviewed journal focusing on the application of nanotechnology in diagnostics, therapeutics, and drug delivery systems throughout the biomedical field. This journal is indexed on PubMed Central, MedLine, CAS, SciSearch ${ }^{\mathbb{}}$, Current Contents ${ }^{\mathbb{R}} /$ Clinical Medicine,

\section{Dovepress}

Journal Citation Reports/Science Edition, EMBase, Scopus and the Elsevier Bibliographic databases. The manuscript management system is completely online and includes a very quick and fair peer-review system, which is all easy to use. Visit http://www.dovepress.com/ testimonials.php to read real quotes from published authors. 